DOI 10.37882/2223-2974.2020.11.14

\title{
ОСОБЕННОСТИ ПРИМЕНЕНИЯ БИЗНЕС-АНАЛИЗА ДЛЯ УСПЕШНОГО ВНЕДРЕНИЯ ІТ-СИСТЕМ В КОМПАНИИ
}

\section{FEATURES OF USING BUSINESS ANALYSIS FOR SUCCESSFUL IMPLEMENTATION IT SYSTEMS IN THE COMPANY}

I. Zakharenkova

T. Belyaeva

T. Terenteva

Summary: The purpose of the article is to assess the importance of business analysis in the context of new IT initiatives. The authors analyze challenges of IT systems implementation and the role that business analyst can play to mitigate the risk and enable smoother adoption. An example of efficient application of business analysis techniques is given using a case study of CRM implementation. The article proposes the analysis of six techniques including their description, goal and benefit for the examined project. It also includes an action plan elaborated based on the analysis results and its positive impact on the company.

Keywords: business analysis, business analyst, IT systems implementation.
Захаренкова Ирина Анатольевна

К.э.н., дочент, Санкт-Петербургский государственный лесотехнический университет им. С.М. Кирова - СПбГЛту,

2. Санкт-Петербург irina_hs@bk.ru

Беляева Татьяна Павловна

К.э.н., дочент, Санкт-Петербургский государственный лесотехнический университет им. С.М. Кирова - СПбГЛту,

г. Санкт-Петербург

tatiana.belyaeva@yahoo.com

Терентьева Татьяна Олеговна

К.э.н., доцент, Санкт-Петербургский государственный университет - СПбГУ, г. Санкт-Петербург terenteva-to@yandex.ru

Аннотация: Целью написания статьи является оценка важности применения бизнес-анализа в контексте новых ІТ-инициатив. Авторы анализируют проблемы внедрения IT-систем и роль, которую может сыграть бизнес-анализ для снижения риска и обеспечения более гибкого принятия решений. Пример эффективного применения методов бизнес-анализа приведен на базе внедрения CRM. В статье предлагается обзор шести методов, включая их описание, цель и полезность для рассматриваемого проекта. В статье также предложен план действий, разработанный на основе результатов анализа, и дана оценка его положительного влияния на деятельность компании.

Ключевые слова: бизнес-анализ, бизнес-аналитик, внедрение информационных систем, CRM.

ется последовательное документирование требований и результатов, являющихся частью области исследования бизнес-анализа. Это позволяет эффективно передавать информацию участникам проекта и обеспечивать удобную коммуникацию.

\section{Проблемы внедрения новых IT-систем}

Оставляя в стороне вопросы эффективного проектирования программного обеспечения и инфраструктуры, следует отметить, что еще одной главной проблемой является настройка и внедрение систем. В каждом крупном проекте длительность периода перехода вводится в цену и планирование, составляя в среднем 10-20\% от продолжительности проекта.

В течение этого времени специалисты помогают пользователям переходить от устаревшего программного обеспечения к новому. Но в маломасштабном проекте этим процессом часто пренебрегают, и у пользователей остаются полуконфигурированные системы и нехватка знаний для обеспечения их правильного использования [2, с. 18-21]. Именно в таких случаях использование биз- 
нес-аналитики особенно ценно для создания недостающих процессов и обучения персонала на них.

\section{Роль бизнес-аналитика}

Бизнес-анализ - это относительно новая область исследований, возникшая как практическая дисциплина, отвечающая на прямую необходимость создания дополнительного слоя между техническими специалистами по IT-системам и бизнесом. Являясь мостом между IT-системами и бизнесом, бизнес-аналитик играет роль, которая имеет два основных аспекта.

1. Переводчик с языка IT-систем на язык бизнеса и обратно. Чтобы эффективно выполнять эту функцию, бизнес-аналитик должен обладать двойной компетенцией: техническими знаниями ITсистем, чтобы иметь возможность общаться с разработчиками, и глубоким знанием специфики компании и отрасли для лучшего понимания протекающих бизнес-процессов. В зависимости от уровня организации бизнеса компании бизнесаналитик должен обладать различным уровнем IT-ориентированности в рамках деятельности компании, которая может варьироваться от 50:50 до 80:20 [6, с. 12].

2. Организатор. В зависимости от того, есть ли в проекте менеджер проекта или нет, бизнес-аналитик возьмет на себя большую или меньшую часть организационных обязанностей. Но в любом случае это будет важной составляющей работы по организации сотрудничества нескольких заинтересованных сторон.

Многие проблемы и препятствия для успешного внедрения и последующего использования систем возникают из-за отсутствия структуры и связи. Инфраструктура заинтересованных сторон не является самоорганизующейся системой и требует тщательного планирования и управления. Простое действие, например, объединение всех соответствующих заинтересованных сторон на одном собрании для обсуждения проблем с четким планом и действиями, назначенными для соответствующих сотрудников, может помочь решить немало проблем [3, с. 45].

Некоторые проблемы приобретают преувеличенную сложность только из-за отсутствия общего понимания и фрагментарного знания предмета проблемы, рассредоточенной по различным субъектам.

\section{Источники информации по бизнес-анализу}

Можно выделить три основных источника информации по бизнес-анализу:
1. Основным и, вероятно, наиболее известным стандартом для практики бизнес-анализа является «Руководство ВАВОК» (Руководство по совокупности знаний по бизнес-анализу), опубликованное МИБА (Международный институт бизнес-анализа) (2015). Справочник был впервые опубликован в 2006 году, и улучшается благодаря новым методам и подходам, а его третье и текущее издание было опубликовано в 2015 году.

2. Другой менее известной книгой является «Книга наставника бизнес-аналитика» Эмры Яйчи (2013), которая также полезна для понимания роли бизнес-анализа.

3. Но основная информация по бизнес-анализу представлена в интернет-источниках. Одним из самых популярных из них является блог Романа Пихлера (www.romanpichler.com), в котором содержится обширный комплекс статей о владении продуктами бизнес-анализа.

\section{Методы бизнес-анализа}

Руководство ВАВОК содержит описание 50 различных методов бизнес-анализа. Чтобы показать образец его применения, полезного для бизнеса, рассмотрим простой пример.

Новая система (CRM - Управление взаимоотношениями с клиентами) внедряется в компании без надлежащей методологии, что приводит к неспособности персонала должным образом использовать ее функциональные возможности. Эта ситуация уже освещалась Ullah, Iqbal and Shams (2020) или Gavval and Ravi (2020) в качестве примера для банковской индустрии [4, с. 59-77].

В приведенной ниже таблице 1 представлены различные методы, которые можно использовать для проведения бизнес-анализа в случае внедрения CRM.

Таким образом, проведенный бизнес-анализ в описанном выше тематическом исследовании позволил определить ход действий по повышению эффективности использования CRM.

Анализ документов в сочетании с анализом основных причин позволил выявить следующие проблемы: отсутствие понимания системы непосредственными пользователями (маркетинговая группа) по ряду причин: неполная настройка со стороны поставщика, отсутствие обучения, координации и поддержки со стороны IT-команды. 
Таблица 1.

Методы бизнес-анализа, применимые в тематическом исследовании внедрения CRM

\begin{tabular}{|c|c|c|c|}
\hline Техника & Описание & Цель & $\begin{array}{c}\text { Преимущество } \\
\text { (тематическое исследование) }\end{array}$ \\
\hline $\begin{array}{l}\text { Анализ } \\
\text { заинтересованных } \\
\text { сторон }\end{array}$ & $\begin{array}{l}\text { Несколько методов могут быть использованы } \\
\text { для определения соответствующих заинтересо- } \\
\text { ванных сторон: } \\
\text { 1. Списки заинтересованных сторон. } \\
\text { 2. Карты заинтересованных сторон (матрица } \\
\text { заинтересованных сторон, луковая диаграмма } \\
\text { или матрица RACI). } \\
\text { 3. Персоны: архетип, который иллюстрирует } \\
\text { способ взаимодействия определенного типа } \\
\text { пользователей с системой. }\end{array}$ & $\begin{array}{l}\text { Выявить заинтересованные сто- } \\
\text { роны, на которые могут повлиять } \\
\text { изменения в системе, принимаю- } \\
\text { щие решения или нуждающиеся в } \\
\text { информировании. }\end{array}$ & $\begin{array}{l}\text { Матрица RACI используется для обеспече- } \\
\text { ния того, чтобы все требования были со- } \\
\text { браны, и для разработки плана коммуни- } \\
\text { каций, чтобы снизить риск раздробленных } \\
\text { знаний об использовании системы. }\end{array}$ \\
\hline Анализ причин & $\begin{array}{l}\text { Диаграмма Fishbone наиболее широко исполь- } \\
\text { зуется вместе с техникой Five Whys (неодно- } \\
\text { кратно задавая вопрос «Почему?»). }\end{array}$ & $\begin{array}{l}\text { Позволяет определить глубин- } \\
\text { ную причину проблемы, чтобы } \\
\text { исправить саму проблему, а не ее } \\
\text { последствия. }\end{array}$ & $\begin{array}{l}\text { Анализ выявил множество основных } \\
\text { причин, например: отсутствие подотчет- } \\
\text { ности поставщика, отсутствие мотивации } \\
\text { ІТ-персонала, вызванное устойчивыми не- } \\
\text { выгодными отношениями с маркетингом. }\end{array}$ \\
\hline $\begin{array}{l}\text { Анализ докумен- } \\
\text { тов }\end{array}$ & $\begin{array}{l}\text { Состоит в просмотре документации по текуще- } \\
\text { му решению с соответствующими примечани- } \\
\text { ями. }\end{array}$ & $\begin{array}{l}\text { Лучше понять текущую реализацию } \\
\text { и процессы вокруг нее, концентри- } \\
\text { руясь на обнаружении неэффектив- } \\
\text { ности. }\end{array}$ & $\begin{array}{l}\text { Анализ руководств пользователя показал, } \\
\text { что они были написаны пользователями, } \\
\text { не полностью знакомыми с решением, и } \\
\text { содержат упущения или необдуманные } \\
\text { обходные пути. }\end{array}$ \\
\hline $\begin{array}{l}\text { Моделирование } \\
\text { процесса }\end{array}$ & $\begin{array}{l}\text { Визуальное представление рабочего процесса } \\
\text { в графической модели, обычно выполняемой с } \\
\text { помощью приложения для создания диаграмм, } \\
\text { такого как MS Visio. }\end{array}$ & $\begin{array}{l}\text { Определить текущий и будущий } \\
\text { рабочий процесс, участников, аль- } \\
\text { тернативные пути и исключения. }\end{array}$ & $\begin{array}{l}\text { Визуальное представление потока } \\
\text { процесса позволяет упростить задачу } \\
\text { оптимизации действий, а также предо- } \\
\text { ставить документацию для дальнейшего } \\
\text { использования. }\end{array}$ \\
\hline Анализ разрыва & $\begin{array}{l}\text { Анализирует разницу между бизнес-требова- } \\
\text { ниями и текущими возможностями, и состоит } \\
\text { в описании текущего состояния, будущего } \\
\text { состояния, разрыва между ними и возможных } \\
\text { решений. }\end{array}$ & $\begin{array}{l}\text { Наметить курс действий, чтобы } \\
\text { приблизить текущее состояние к } \\
\text { желаемому. }\end{array}$ & $\begin{array}{l}\text { Анализ показал необходимость настроить } \\
\text { дополнительные функции в (RM, чтобы } \\
\text { иметь возможность выполнять весь } \\
\text { спектр или требуемые задачи. }\end{array}$ \\
\hline Бизнес-кейс & $\begin{array}{l}\text { Документ, состоящий из следующих элементов: } \\
\text { 1. Оценка потребностей: определяет проблему } \\
\text { или потенциальную возможность. } \\
\text { 2. Желаемые результаты: описывает будущее } \\
\text { состояние, если потребность удовлетворена, } \\
\text { причем она должна быть измеримой. } \\
\text { 3. Альтернативы: оценка каждого альтерна- } \\
\text { тивного решения (технологии или процесса) } \\
\text { с точки зрения его масштабов, осуществимо- } \\
\text { сти, допущений и рисков, а также стоимости } \\
\text { реализации. } \\
\text { 4. Рекомендуемое решение: описывает лучшее } \\
\text { решение, его стоимость и продолжительность } \\
\text { его реализации. }\end{array}$ & $\begin{array}{l}\text { Предоставить обоснование и } \\
\text { порядок действий для внедрения } \\
\text { дополнительного программного } \\
\text { обеспечения или изменения про- } \\
\text { цесса. }\end{array}$ & $\begin{array}{l}\text { Внедрение стороннего программного обе- } \\
\text { спечения позволило упростить и ускорить } \\
\text { загрузку данных в систему. }\end{array}$ \\
\hline
\end{tabular}

*Источник: на основе «Руководства ВАВОК» [1] 
Моделирование процессов с помощью потоковой диаграммы помогло изменить части существующего рабочего процесса, чтобы упростить его. В ходе анализа пробелов были предложены следующие решения: бизнес-аналитик должен выступить в качестве посредника в отношениях между IT-отделом и маркетинговой командой, внешний консультант должен быть приглашен для завершения необходимых настроек и проведения обучения для команды. Анализ также выявил техническую проблему, связанную с потоком данных между CRM и другими системами, которая должна быть решена путем введения стороннего инструмента, предназначенного для частичной автоматизации загрузки данных.

Бизнес-кейс создается для получения подписанного бюджета на реализацию. Использование инструмента бизнес-анализа, а также привлечение бизнес-аналитика помогли автоматизировать список задач, связанных с маркетингом, обеспечивая экономию времени, повышение эффективности деятельности маркетинговых кампаний, а также улучшение взаимоотношений между IT и бизнесом.

\section{ЛИТЕРАТУРА}

1. A Guide to the Business Analysis Body of Knowledge v3', (2015), International Institute of Business Analysis (IIBA), https://www.iiba.org/standards-and-resources/ babok/

2. Aghabaghery, R., Hashemi Golpayegani, A. and Esmaeili, L. (2020) 'A new method for organizational process model discovery through the analysis of workflows and data exchange networks' Social Network Analysis and Mining, 10(1), 12.

3. Gavval, R. and Ravi, V. (2020) 'Clustering bank customer complaints on social media for analytical CRM via multi-objective particle swarm optimization' Studies in Computational Intelligence, SCI 871, 213-239.

4. Ullah, A., Iqbal, S. and Shams, S.M.R. (2020) 'Impact of CRM adoption on organizational performance: Moderating role of technological turbulence' Competitiveness Review, 30(1), 59-77.

5. Yayici, E. (2013) Business Analyst's mentor book', Amazon, UK, ISBN: 6-05-860371-4.
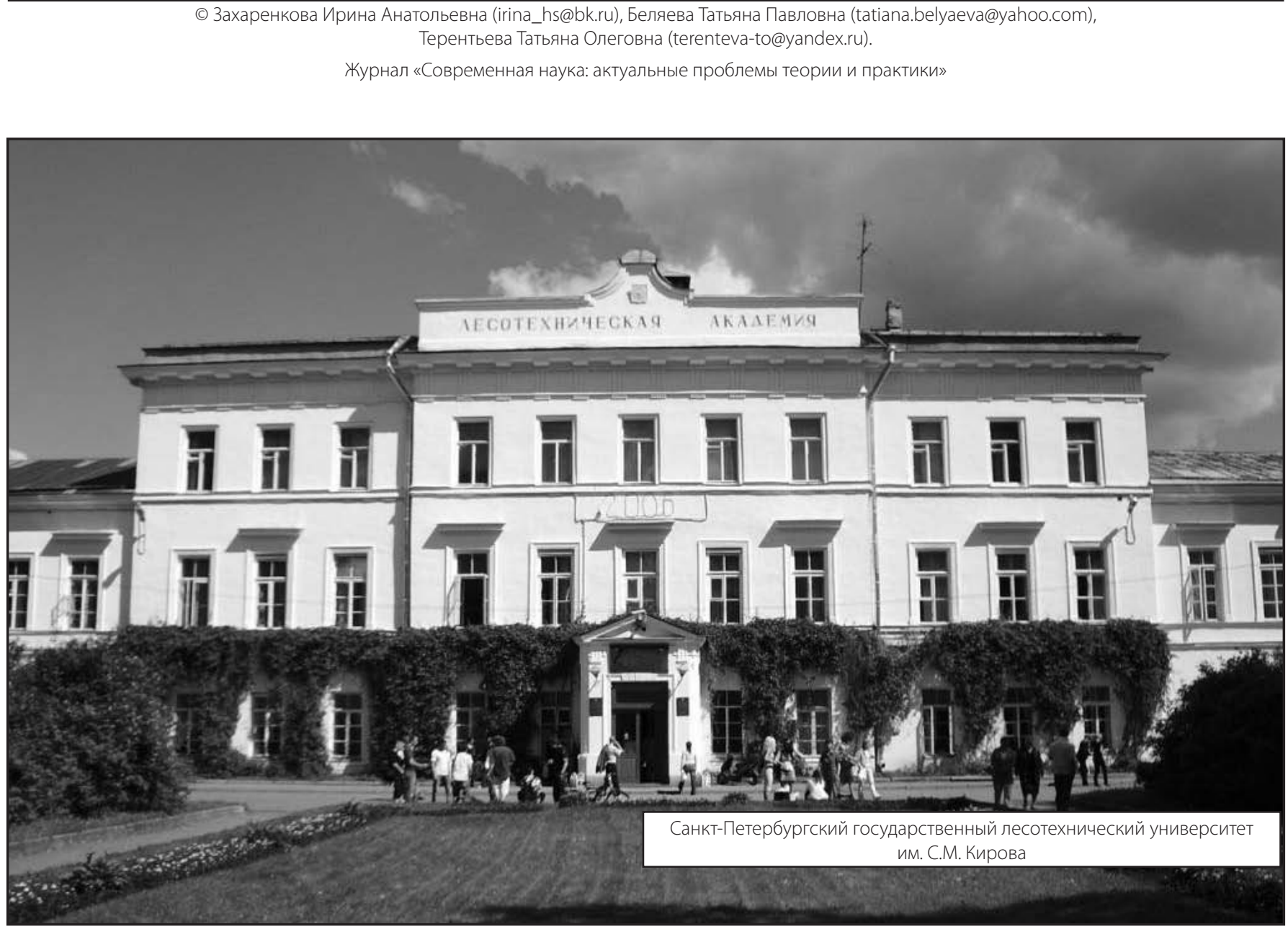